\title{
Homeobox genes and connective tissue patterning
}

\author{
Guillermo Oliver ${ }^{1, \star}$, Roland Wehr ${ }^{1}$, Nancy A. Jenkins ${ }^{2}$, Neal G. Copeland ${ }^{2}$, Benjamin N. R Cheyette ${ }^{3}$, \\ Volker Hartenstein ${ }^{4}$, S. Lawrence Zipursky ${ }^{3}$ and Peter Gruss ${ }^{1}$ \\ ${ }^{1}$ Department of Molecular Cell Biology, Max Planck Institute of Biophysical Chemistry, Am Fassberg, 37077 Göttingen, Germany \\ ${ }^{2}$ Mammalian Genetics Laboratory, ABL-Basic Research Program, NCl-Frederick Cancer Research and Development Center, \\ Frederick, MD 21702, USA \\ ${ }^{3}$ Department of Biological Chemistry and Howard Hughes Medical Institute, University of California, Los Angeles, California \\ 90024-1662, USA \\ ${ }^{4}$ Department of Biology, University of California, School of Medicine, Los Angeles, California 90024-1737, USA \\ ${ }^{*}$ Author for correspondence
}

\section{SUMMARY}

In vertebrates, limb tendons are derived from cells that migrate from the lateral plate mesoderm during early development. While some of the developmental steps leading to the formation of these tissues are known, little is known about the molecular mechanisms controlling them. We have identified two murine homeobox-containing genes, Six 1 and Six 2, which are expressed in a complementary fashion during the development of limb tendons. Transcripts for both genes are found in different sets of phalangeal tendons. Six 1 and Six 2 also are expressed in skeletal and smooth muscle, respectively. These genes may participate in the patterning of the distal tendons of the limb phalanges by setting positional values along the limb axes.

Key words: connective tissue, tendons, muscle, homeobox, embryogenesis, murine, limb, splotch

\section{INTRODUCTION}

The development of the vertebrate limb is a popular system for studying the mechanisms controlling patterning and morphogenesis. These studies have focussed on formation of the skeletal limb elements and, more recently, muscle formation (Saunders, 1977; Shellswell and Wolpert, 1977; Robson et al., 1994). In contrast, mechanisms leading to the final patterning of the limb tendons have received little attention. A description of tendon formation, as well as some experimental manipulations suggesting the involvement of an extracellular matrix scaffold in the patterning of the long tendons of the digits have been reported (Sullivan, 1962; Hurle et al., 1990).

Removal of the apical ectodermal ridge (AER), produced truncated digits missing one or two phalanges (Hurle et al., 1990). The extensor and flexor tendons of the missing phalanges extended distally, joining each other over the region that correspond to the missing phalange in a similar way to that which occurs in the normal digits. This suggests that the growing and maybe the patterning of the tendons is independent of skeletal elements, and hence muscles, and also that primary muscle patterning is determined by the local connective tissue-forming mesenchyme (Chevallier and Kieny, 1982). Transplanted unsegmented thoracic mesoderm can replace the brachial somites. The ability of the transplanted mesoderm to form normal brachial musculature indicates that the environment controls mesodermal patterning (Butler et al., 1988). Consistent with the findings, distal limb tendons can be formed without muscles, though tendons require muscle for survival otherwise they will degenerate (Shellswell and Wolpert, 1977; Kieny and Chevallier, 1979).

Members of the Hox family of genes are differentially expressed in mesenchymal cells that will give rise to the limb skeletal structures, and probably also to connective tissue (for a review see Morgan and Tabin, 1993). The positional values of the skeletal components along the body axes may be determined by the Hox genes. Despite the great number of vertebrate homeobox genes already isolated, no specific expression in tendons or ligaments has been reported for any of them. Hence, it is likely that a distinct molecular mechanism responsible for the patterning of the limb long tendons exists (Hurle et al., 1990).

In this paper, we describe the isolation and characterization of two novel murine homeobox-containing genes. These genes designated Six 1 and Six 2 were cloned by homology to sine oculis, a recently described Drosophila gene (Cheyette et al., 1994). They share extensive similarities within and outside the homeodomain to each other as well as to the corresponding fly gene.

In the limb buds, transcripts are initially found in connective tissue-precursor cells. Later, transcripts become differentially localized to specific subsets of limb tendons, with Six 1 largely restricted to the dorsal extensor tendons of the digits, and Six 2 to the ventral flexor ones. Six 1 and Six 2 appear to be the first specific molecular markers reported for the limb tendons. 
A

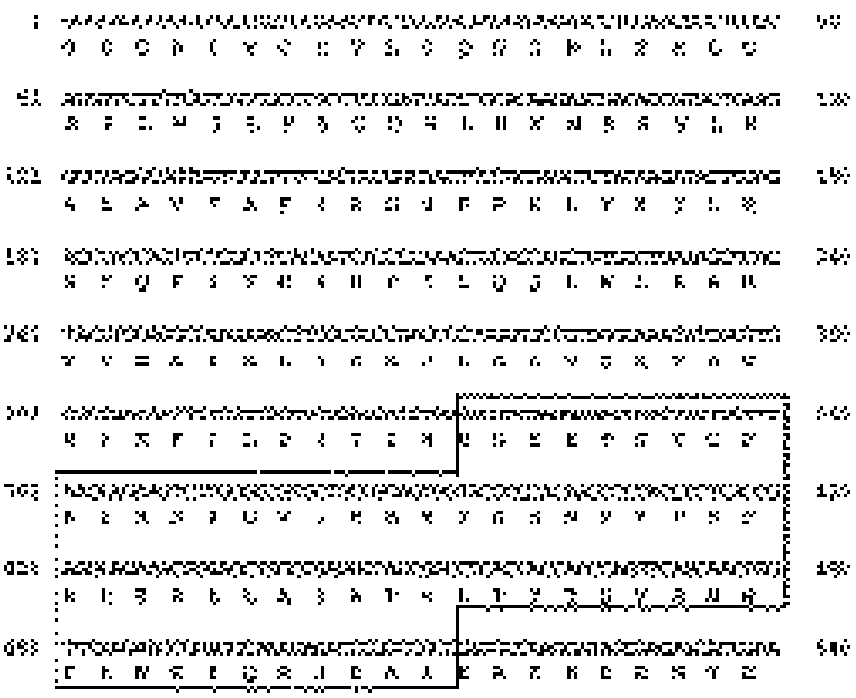

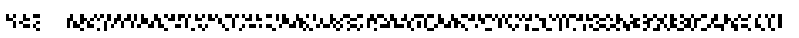

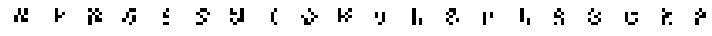

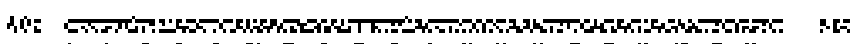

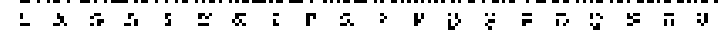

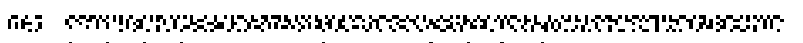

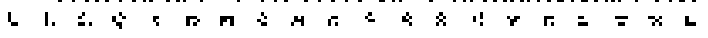

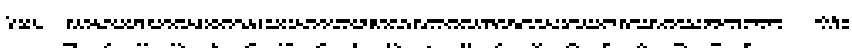

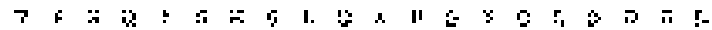

7)

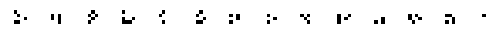

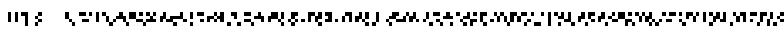

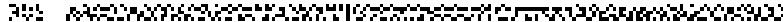
ני 1.

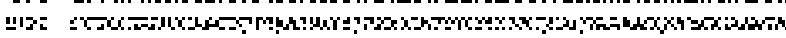

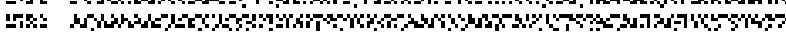

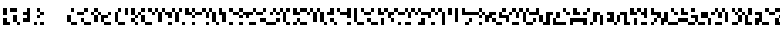

ît

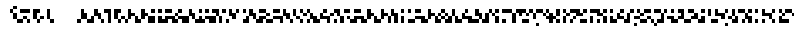

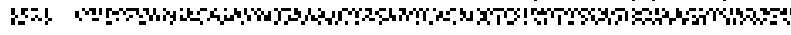

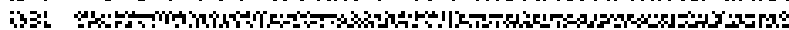

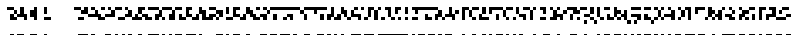

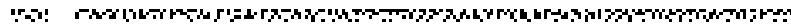

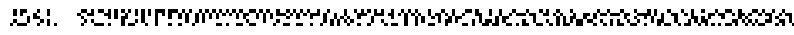

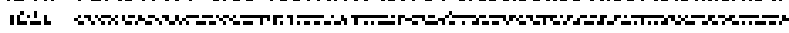

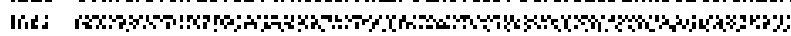

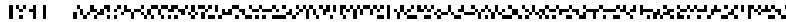

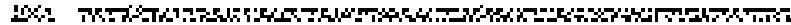

IIF, 1.

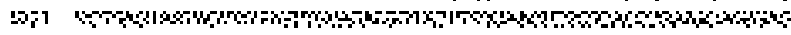

wh n

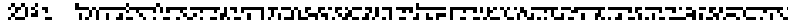

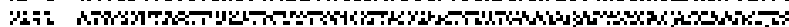

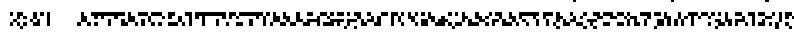

7xi

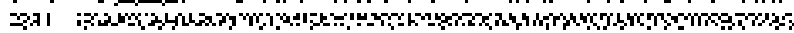

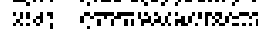

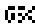

7

$4:$ $\because$ 4 it!'

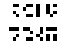
$2 \mathrm{rat}$ Fis J.:-1: sit Jitín arit $\sin$ 40

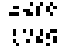

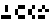
I:at; -ain :at: 216 ?lit:

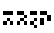
Fis inti:
\#

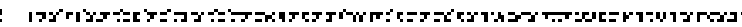

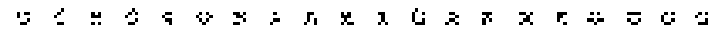

s $\Rightarrow \quad \sigma \quad \sigma \quad$ l.

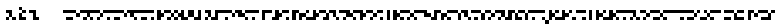
1: ".

- 1.

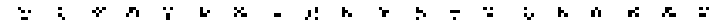

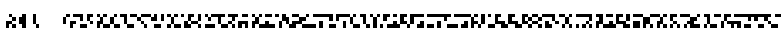

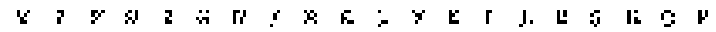

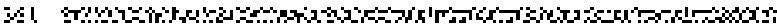

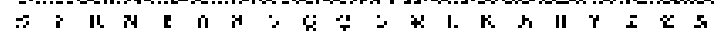

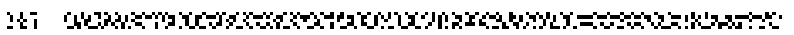

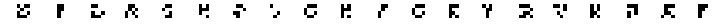

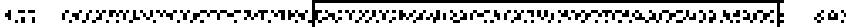

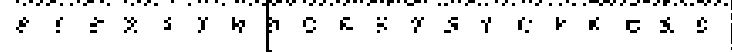

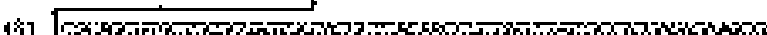

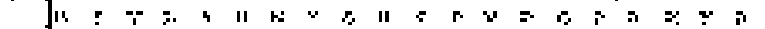

$\rightarrow 4.13$

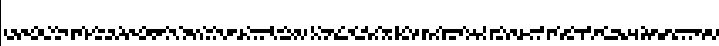

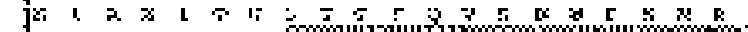

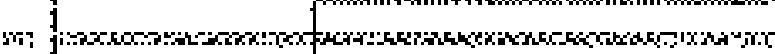
1

t:

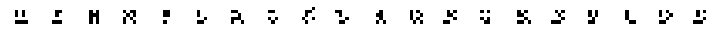

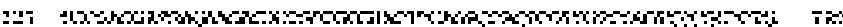

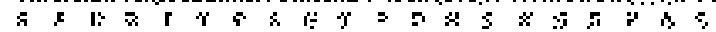

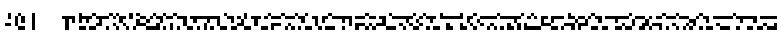

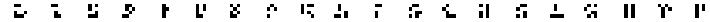

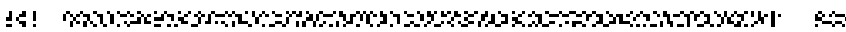

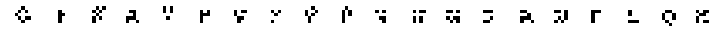

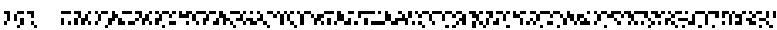

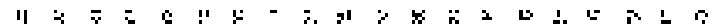

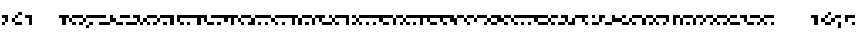
5

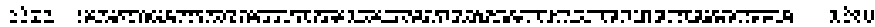

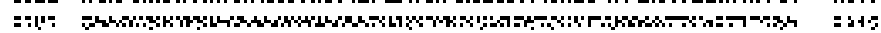

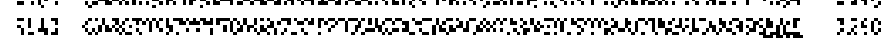

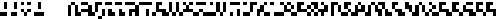

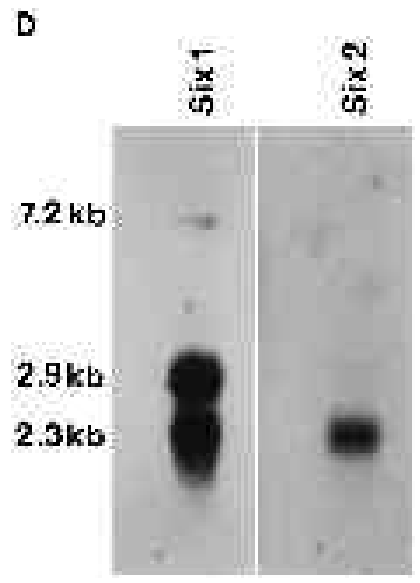

Fig. 1. Molecular characterization of Six 1 and Six 2. Nucleotide sequence of Six 1 (A) and Six 2 (B) cDNAs and predicted amino acid sequences. Boxed amino acid sequence corresponds to the homeodomain The underlined sequence is the putative polyadenylation signal (poly A tail is missing in Six 1 cDNA). (C) Comparison of the Drosophila so homeodomain (Cheyette et al., 1994), with those of Six 1 and Six 2. (D) Northern blot analysis of Six 1 and Six 2 transcripts. The size of the transcripts is indicated on the left and was estimated by comparison with the RNA ladder (Boheringer) (not shown). EMBL Accession numbers: X80339 (Six 1), X80338 (Six 2 ). 
During early mouse development, Six 1 and Six 2 transcripts also are found in different tissues. Six 1 is expressed in some mesodermally derived tissues including skeletal muscle, as well as in dorsal root ganglia and Rathke's pouch. Six 2 transcripts accumulate in some visceral smooth muscle, metanephros, genitalia and also in a restricted cell population of the hindbrain. Later, it also is found in some head bones. Six 1 and Six 2 map to chromosome 12 and chromosome 17, respectively.

\section{MATERIALS AND METHODS}

\section{Isolation of Six 1 and Six 2 cDNAs}

A short region of the Drosophila sine oculis cDNA spanning the homeobox and additional $5^{\prime}$ and $3^{\prime}$ flanking sequences was used to probe an amplified 8.5 days post-coitum C57BL murine $\lambda$ gt 10 library (kindly provided by Dr Brigid Hogan, Vanderbilt University Medical School). Hybridization was performed at $43^{\circ} \mathrm{C}$ in hybridization buffer (43\% formamide, $5 \times$ Denhardt's, $5 \times$ SSC, $0.02 \%$ sodium pyrophosphate, $100 \mu \mathrm{g} / \mathrm{ml}$ Torula RNA, 0.1\% SDS, $125 \mathrm{U} / \mathrm{ml}$ heparin, $0.03 \mathrm{M}$ sodium phosphate, $\mathrm{pH} 6.5$ ). Filters were washed three times with $2 \times$ SSC, $0.1 \%$ SDS at $42^{\circ} \mathrm{C}$ and twice with $0.5 \times$ SSC, $0.1 \%$ SDS at $65^{\circ} \mathrm{C}$. In order to obtain full-length cDNAs for both genes, an amplified 12.5 day post-coitum $\mathrm{C} 3 \mathrm{H}$ murine $\lambda \mathrm{gt} 10 \mathrm{cDNA}$ library (kindly provided by Dr Gail Martin, University of California at San Francisco) was screened with the most $5^{\prime}$ region of the $\sim 2.4 \mathrm{~kb}$ Six 1 and the $\sim 1.2 \mathrm{~kb}$ Six 2 clones, but we did not succeed in obtaining the missing sequence. Using the $5^{\prime}$ race technique (Frohman et al., 1988), we also were unable to further extend the available sequences of these genes.

\section{Chromosomal localization of Six 1 and Six 2}

Interspecific backcross progeny were generated by mating $(\mathrm{C} 57 \mathrm{BL} / 6 \mathrm{~J} \times M$. spretus) $\mathrm{F}_{1}$ females and $\mathrm{C} 57 \mathrm{BL} / 6 \mathrm{~J}$ males as described (Copeland and Jenkins, 1991). A total of $205 \mathrm{~N}_{2}$ mice were used to map the Six 1 and Six 2 loci (see text for details). DNA isolation, restriction enzyme digestion, agarose gel electrophoresis, Southern blot transfer and hybridization were performed essentially as described (Jenkins et al., 1982). All blots were prepared with Hybond-N ${ }^{+}$ nylon membrane (Amersham). The Six 1 probe, an $\sim 960$ bp EcoRI fragment of mouse cDNA, detected major fragments of 12.5, 6.5 and $2.6 \mathrm{~kb}$ in C57BL/6J (B) DNA and $12.5,9.0$, and $2.6 \mathrm{~kb}$ in M. spretus $(\mathrm{S})$ DNA following digestion with HindIII. The Six 2 probe, an $~ 600$ bp PstI fragment of mouse cDNA, detected major BamHI fragments of 8.0, 3.7 and $2.5 \mathrm{~kb}(\mathrm{~B})$ and $8.0,4.5$ and $1.9 \mathrm{~kb}(\mathrm{~S})$. The presence or absence of $M$. spretus-specific fragments was followed in backcross mice.

A description of the probes and RFLPs for the loci used to position the Six loci in the interspecific backcross has been reported. These include: Sos2, Spnbl and Fos for chromosome 12 (Webb et al., 1993) and Tik, Sosl and Lhcgr for chro- mosome 17 (Fishel et al., 1993). Recombination distances were calculated as described (Green, 1981) using the computer program SPRETUS MADNESS. Gene order was determined by minimizing the number of recombination events required to explain the allele distribution patterns.

\section{Northern blot analysis}

RNA was extracted from E10.5 NMRI mouse embryos using the lithium chloride-urea method described by Auffray and Rougeon (1980). Total RNA was poly(A) selected by fractionating total RNA on columns containing Poly(U) Sepharose4B (Pharmacia). Poly(A) RNA $(5 \mu \mathrm{g})$ were electrophoresed in a $1.2 \%$ agarose-formaldehyde gel and transferred to nylon membrane (Qiagen). Hybridization with the Six 1 and Six 2 probes was performed at $65^{\circ} \mathrm{C}$ in buffer adjusted to $50 \%$ formamide, $5 \times \mathrm{SSC}, 5 \times$ Denhardt's, $0.02 \%$ sodium pyrophosphate, $0.1 \%$ SDS, and $50 \mu \mathrm{g} / \mathrm{ml}$ salmon sperm DNA. Washes with increasing stringency were performed, the last being at $65^{\circ} \mathrm{C}$ in $0.1 \times$ SSC, $0.1 \%$ SDS.

\section{In situ hybridization}

Embryos were dissected, fixed overnight in $4 \%$ paraformaldehyde and embedded in Paraplast (Monoject Scientific). Sections $(8 \mu \mathrm{m})$ were cut and dried onto chromalum-gelatin slides. All the steps of highstringency hybridization, washing and RNAse treatment were performed as described previously (Kessel and Gruss, 1991). T3 or T7 RNA polymerase in vitro transcribed sense or antisense ${ }^{35} \mathrm{~S}$ labelled RNA probes were generated from various Bluescript $\mathrm{KS} \mathrm{II}^{+}$
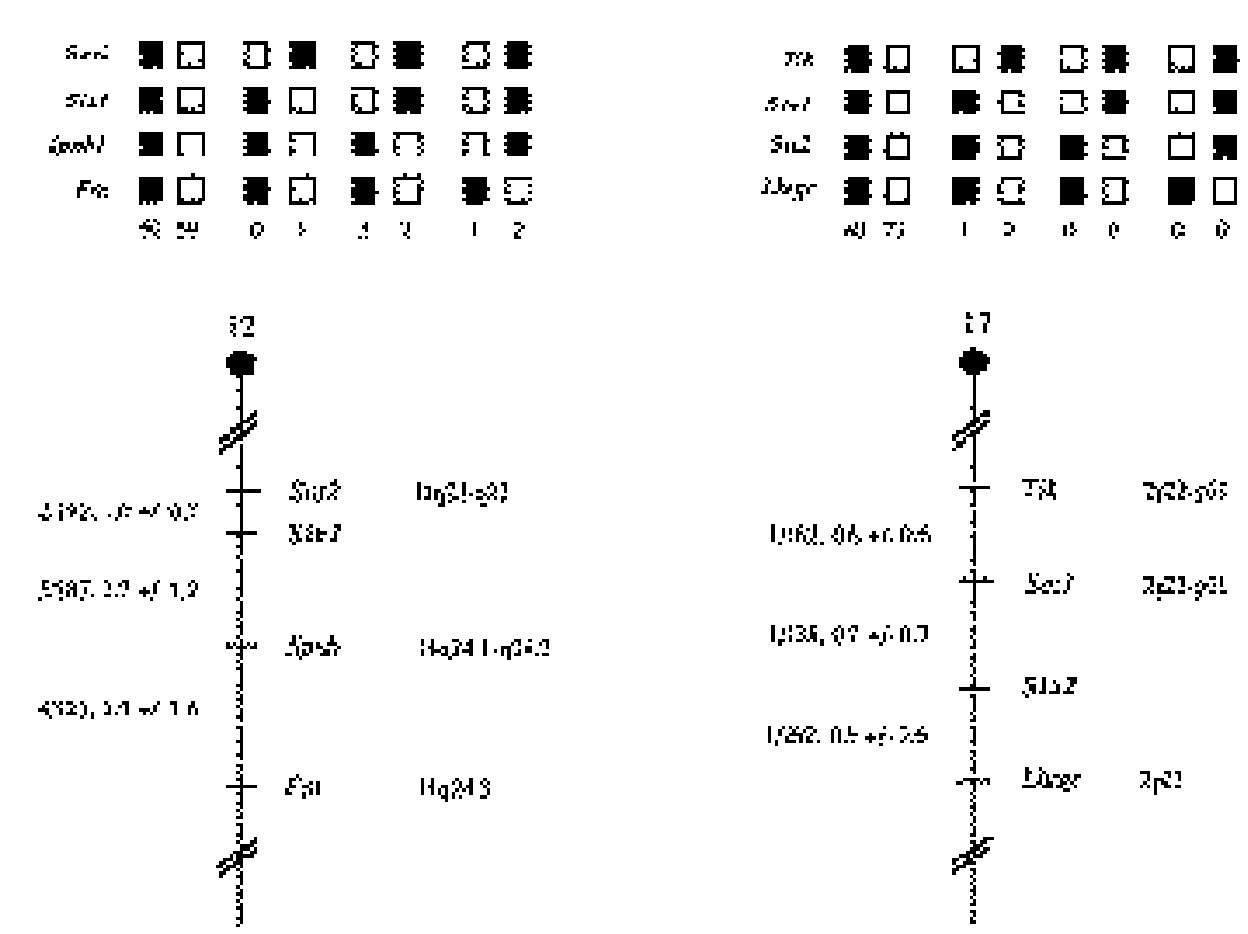

Fig. 2. Chromosomal locations of Six 1 and Six 2 in the mouse genome. Segregation patterns of the loci and flanking genes in backcross animals that were typed for all loci are shown above the chromosome maps. Each column represents the chromosome identified in the backcross progeny that was inherited from the $(\mathrm{C} 57 \mathrm{BL} / 6 \mathrm{~J} \times M$. spretus $) \mathrm{F}_{1}$ parent. The shaded boxes represent the presence of a $\mathrm{C} 57 \mathrm{BL} / 6 \mathrm{~J}$ allele and white boxes represent the presence of a $M$. spretus allele. The number of offspring inheriting each type of chromosome is listed at the bottom of each column. Partial chromosome linkage maps showing the location of Six 1 and Six 2 in relation to linked genes is shown. The number of recombinant $\mathrm{N}_{2}$ animals is presented over the total number of $\mathrm{N}_{2}$ animals typed to the left of the chromosome maps between each pair of loci. The recombination frequencies, expressed as genetic distance in centimorgans $( \pm 1$ standard error) are also shown. The positions of loci in human chromosomes, where known, are shown to the right. 

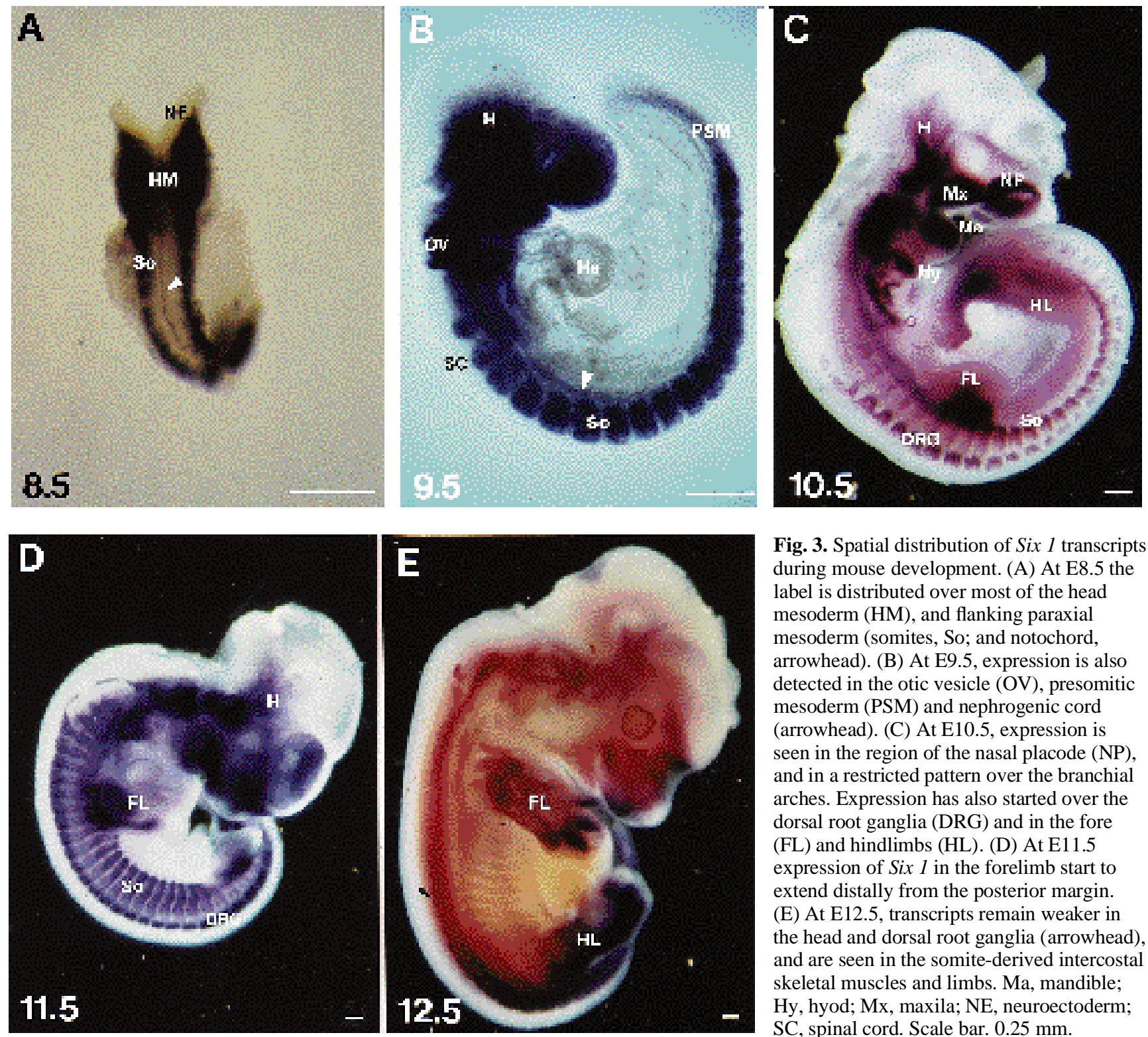

Fig. 3. Spatial distribution of Six 1 transcripts during mouse development. (A) At E8.5 the label is distributed over most of the head mesoderm (HM), and flanking paraxial mesoderm (somites, So; and notochord, arrowhead). (B) At E9.5, expression is also detected in the otic vesicle (OV), presomitic mesoderm (PSM) and nephrogenic cord (arrowhead). (C) At E10.5, expression is seen in the region of the nasal placode (NP), and in a restricted pattern over the branchial arches. Expression has also started over the dorsal root ganglia (DRG) and in the fore (FL) and hindlimbs (HL). (D) At E11.5 expression of Six 1 in the forelimb start to extend distally from the posterior margin. (E) At E12.5, transcripts remain weaker in the head and dorsal root ganglia (arrowhead), and are seen in the somite-derived intercostal skeletal muscles and limbs. Ma, mandible; Hy, hyod; Mx, maxila; NE, neuroectoderm; $\mathrm{SC}$, spinal cord. Scale bar. $0.25 \mathrm{~mm}$.

subclones containing different coding regions of Six 1 and Six 2. The exposure time was approximately 10 days. Whole-mount preparation were proved with digoxigenin-labelled RNA probes and visualized with alkaline phosphatase-coupled anti-digoxigenin antibody and sectioned as described previously (Bober et al., 1994).

\section{RESULTS}

\section{Isolation and characterization of Six 1 and Six 2 cDNAs}

Homeobox-containing genes, such as the vertebrate genes otx1,otx2 and goosecoid, and the invertebrate bicoid, orthodenti cle and EgHbx4 (reviewed in Bürglin, 1994), share a lysine at the position 50 of the recognition helix of the homeodomain. In most cases, these genes are expressed in anterior body structures at early stages of development. In order to identify some novel murine homeobox genes of this type, a DNA fragment of the Drosophila sine oculis gene also containing a lysine at position
50 (Cheyette et al., 1994), was used to probe an amplified E8.5 murine cDNA library. Plaques $\left(10^{6}\right)$ were screened and 7 positives plaques were identified and purified. Five of the clones corresponded to one gene and the remaining two to another. These genes are referred to as Six 1 and Six 2, respectively (Six 1 designates sine oculis-related homeobox). The largest cDNAs obtained for Six 1 was 960 bp, and for Six 2, 800 bp. Northern blot analysis (Fig. 1D) of E10.5 poly(A) mRNA revealed that Six 1 produces three transcripts, two major ones of approximately 2.3 and $2.9 \mathrm{~kb}$, and a weaker one of $7.2 \mathrm{~kb}$ which may represent a form of unprocessed mRNA. Six 2 produces a single transcript of approximately $2.3 \mathrm{~kb}$. In order to obtain full-length cDNAs for Six 1 and Six 2, we used the most $5^{\prime}$ probes of both genes to screen an E12.5 cDNA library. Fourteen clones were isolated, from which 11 were overlapping Six 1 cDNAs and 3 corresponded to Six 2. The longest cDNAs isolated from this screen were $2.4 \mathrm{~kb}$ for Six 1 and $1.2 \mathrm{~kb}$ for Six 2 (Fig. 1A,B). No initiation methionine codon was found in the same open reading frame as the homeodomain suggesting that both cDNAs were not full length. 

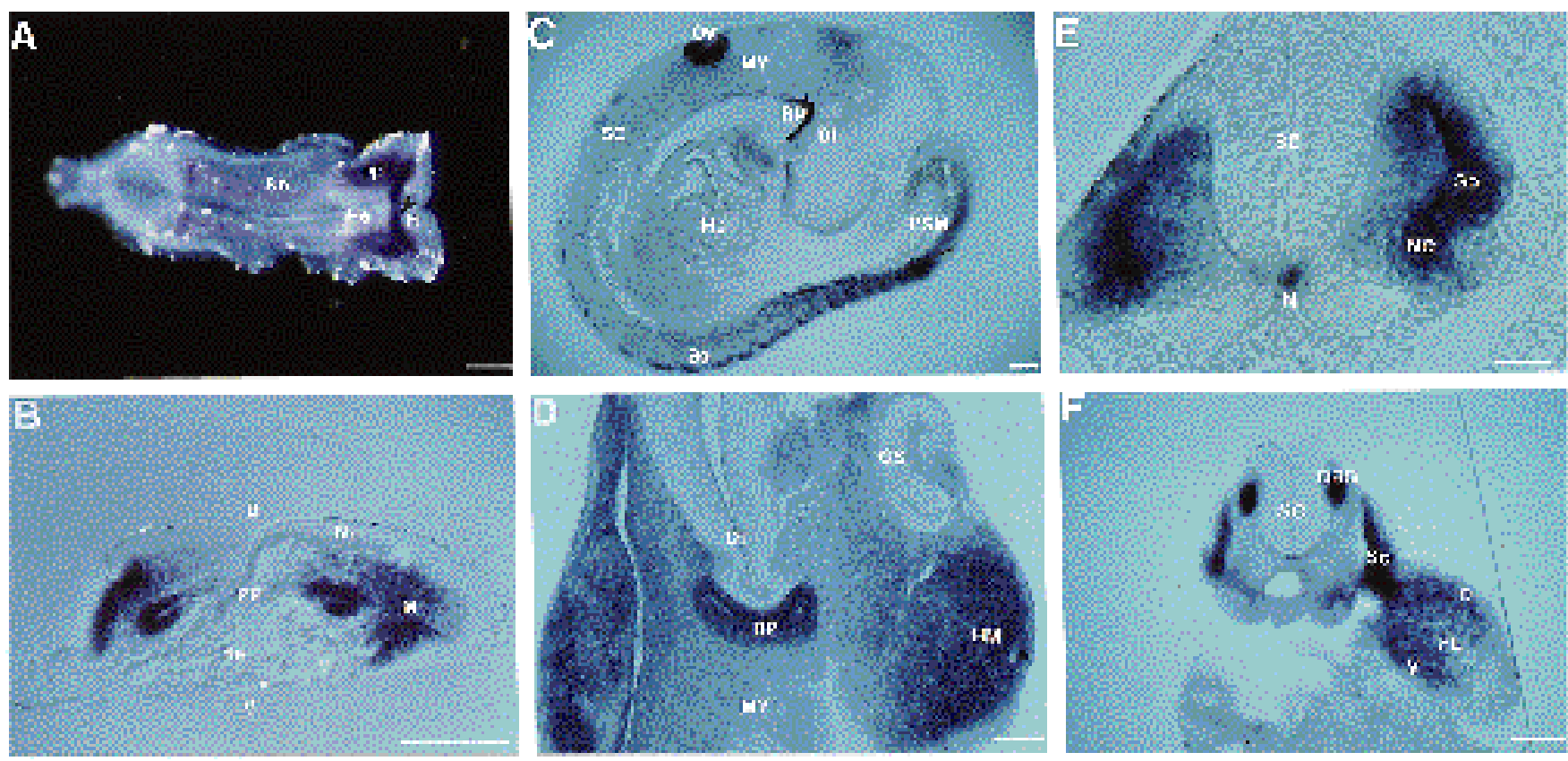

Fig. 4. Six 1 mRNA detection in vibratome sections of whole-mount-stained embryos. (A) Ventral view of a whole early head-fold-stage mouse embryo in which the first detected expression starts as a narrow band over the most anterior head mesoderm (arrowhead) (H). It is also found in the region of the pharyngeal pouches (PP) and paraxial mesoderm (So). (B) Transverse section of an E8.5 embryo in which the head mesoderm is strongly stained (M) as well as the region of the pharyngeal pouches. The neuroectoderm (NE) on the dorsal (D) side, or the heart (He) on the ventral (V) side do not express Six 1 mRNA. (C) Midsaggital section of an E9.5 embryo showing expression in the otic vesicle (OV), Rathke's pouch (RP), somites and presomitic mesoderm (PSM). (D) Transverse section through an embryo similar to that shown in C, in which the expression in the ectodermal-derived Rathke's pouch is more obvious. (E) Transverse section through a more posterior region of an E9.5 embryo showing the positive notochord (N), nephrogenic cords (NC), and expression in the the not yet ventralized somites. F. Transverse section of an E10.5 embryo. At this stage expression is detected in the dorsal root ganglia (DRG) and forelimb (FL), D, dorsal; Di, diencephalon; HM, head mesenchyme; MY, myelencephalon; OS, optic stalk; V, ventral. Scale bar, $0.1 \mathrm{~mm}$.

The predicted amino acid sequences of the murine Six 1 and Six 2 genes and the fly sine oculis (so) gene are highly conserved within the homeodomain and the $5^{\prime}$-flanking region (Fig. 1C). The chicken Six 1 gene also is highly conserved (not shown). The Drosophila so gene and Six 1 are $62 \%$ similar increasing to $87 \%$ if sequences $\mathrm{C}$ terminal to the homeodomain are excluded. Six 2 and so are $76 \%$ similar along the coding regions increasing to $95 \%$ upon exclusion of the homeodomain C-terminal flanking region. Finally, the Six 1 and Six 2 sequences are $76 \%$ similar along the whole coding sequence increasing to $95 \%$ without the $\mathrm{C}$-terminal region flanking the homeodomain. This high similarity extending beyond the homeodomain between the fly and its vertebrate counterparts, is unusual for homeobox-containing genes suggesting the conservation of additional functional domains. The so/Six homeobox is highly distinctive with no more than $30 \%$ identity with previously described homeodomains.

Despite the strong sequence conservation between the Six 1 and Six 2 and sine oculis, neither Six 1 nor Six 2 were found expressed during eye development (see below). However, a recently isolated murine gene, Six 3 (Oliver et al., unpublished results) is strongly expressed in the eye, suggesting that it represents a functional homolog of so. The Six 1, Six 2 and so define a new subclass of homeobox-containing genes.

\section{Chromosomal mapping of Six 1 and Six 2}

The chromosomal location of Six 1 and Six 2 was determined using an interspecific backcross mapping panel derived from crosses of $\left[(\mathrm{C} 57 \mathrm{BL} / 6 \mathrm{~J} \times M\right.$. spretus $\left.) \mathrm{F}_{1} \times \mathrm{C} 57 \mathrm{BL} / 6 \mathrm{~J}\right]$ mice. cDNA fragments from each locus were used as probes in Southern blot hybridization analysis of C57BL/6J and $M$. spretus genomic DNA to identify informative restriction fragment length polymorphisms (RFLPs) useful for gene mapping (see Materials and Methods). The strain distribution pattern (SDP) of each RFLP in the interspecific backcross was then determined by following the presence or absence of RFLPs specific for M. spretus in backcross mice. Six 1 mapped to the central region of mouse chromosome $12,1.0 \mathrm{cM}$ distal of Sos 2 and $2.7 \mathrm{cM}$ proximal of Spnb1. Six 2 mapped to the distal region of mouse chromosome 17, $0.7 \mathrm{cM}$ distal of Sos 1 and $0.6 \mathrm{cM}$ proximal of Lhcgr (Fig. 2).

We have compared our interspecific maps of chromosomes 12 and 17 with composite mutant linkage maps (compiled by M. T. Davisson, T. H. Roderick, A. L. Hillyard, and D. P. Doolittle and provided from GBASE, a computarized database maintained at the Jackson Laboratory, Bar Harbor, ME). There are several mutations in the central to distal region of mouse chromosome 12 (data not shown). One of these is syndactylism $(\mathrm{sm})$. Mice homozygous for this recessive mutation display fused digits on all four feet; many also fail to survive to weaning. (summarized in Green, 1989). The $s m$ mutation has not been precisely mapped on chromosome 12; however, linkage to Aat (formerly Pre1) has been demonstrated in a twopoint cross (Hawes et al., 1980). Given these observations and 
the expression pattern of Six 1, particularly in the limb tendons, $s m$ is an attractive candidate for an alteration in the Six 1 locus. Finally, mutations mapping to the distal region of mouse chromosome 17 in the vicinity of Six 2 have not been reported.

\section{Expression analysis during development}

A detailed analysis of the expression pattern of Six 1 and Six 2 genes was performed using in situ hybridization. Whole-
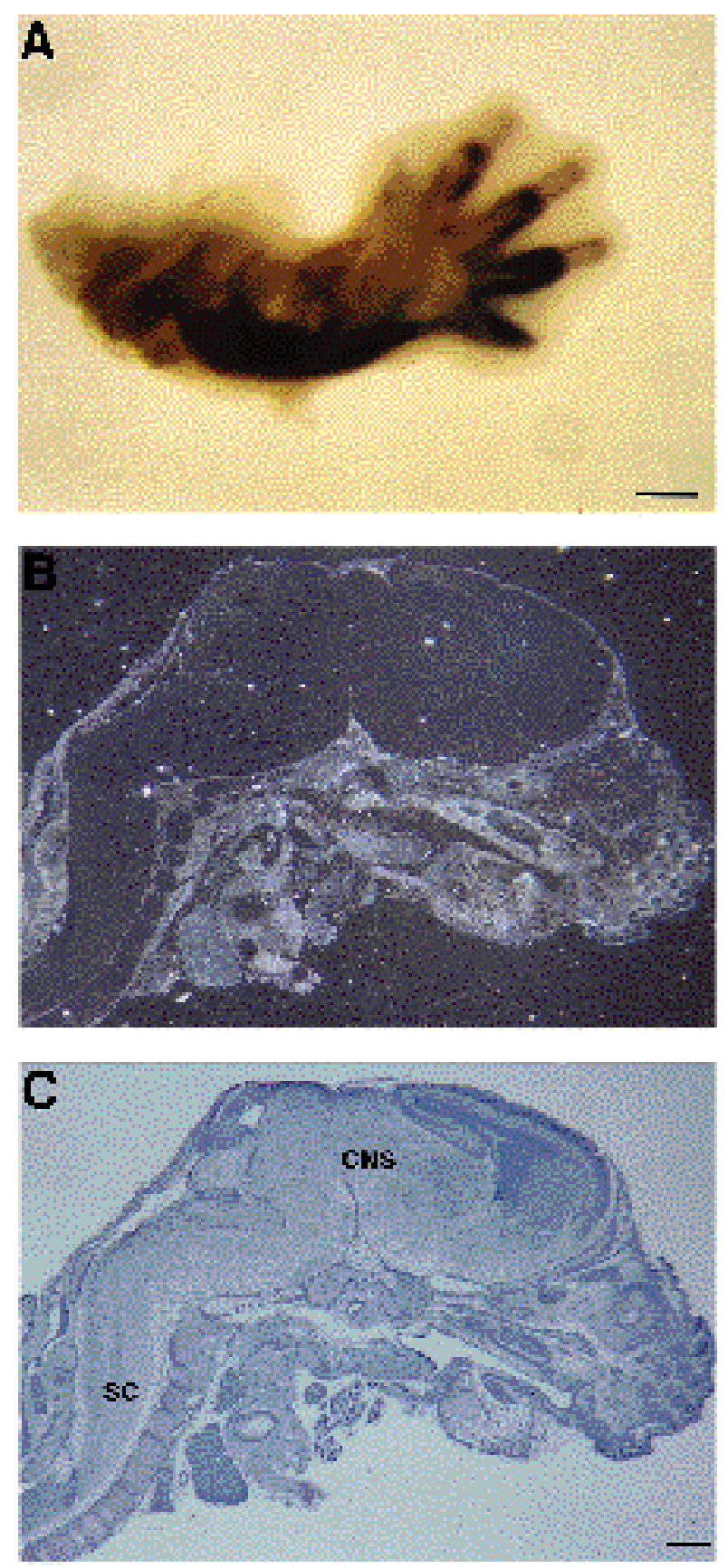

Fig. 5. Six 1 is expressed in head and body skeletal masses. (A) E13.5 whole-mount-stained forelimb bud showing expression in some of the arm muscle fibers as well as in the tendons sourrounding the digits. (B) At E15.5 silver grain accumulation is found over most of the head voluntary muscles. (C) Bright field. CNS, central nervous system. Scale bar, (A) $0.25 \mathrm{~mm}$; (B) $0.5 \mathrm{~mm}$. mount preparations were probed with digoxigenin-labelled RNA and then sectioned. In some cases, in situ hybridization to paraffin sections was performed using radiolabelled probes.

\section{Six 1 gene expression}

Expression of Six 1 is detected first at E8.2-8.5 days of mouse development. It is restricted to a narrow band corresponding to the most anterior head mesoderm and two lateral stripes corresponding to the developing pharyngeal pouches (Fig. 4A,B). As development proceeds, labelling extends posteriorly, to include most of the head mesoderm (Fig. 3A), the precursors to most craniofacial voluntary muscles. The strong head expression probably includes the neural crest-derived connective tissue forming the ectomesenchyme. Expression at this stage is also found in structures derived from the axial and paraxial mesoderm (i.e. the notochord and developing somites (Fig. 3A)).

At E9.5 the earlier staining pattern persists. In addition, Six 1 transcripts are found in some other body regions (Fig. 3B). In the head transcripts are widely distributed. Somites also are strongly labelled (Fig. 4E). The section in Fig. 4E corresponds to a level just anterior to the presomitic mesoderm; at this stage, the somites do not show any indication that the ventral cells are commited to form sclerotome. Later in development, expression in somites is mainly restricted to the dermomyotome, which will later give rise to dermis and to axial and limb muscle (Fig. 4F). Staining also is found in presomitic mesoderm, immediately posterior to the most recently formed somite (Figs 3B, 4C). The otic vesicle, which is composed of neural crest and lateral plate-derived elements (Fig. 4C), and the ectoderm-derived Rathke's pouch (Fig. 4C,D), which later will give rise to the glandular part of the pituitary gland, express Six 1. Finally, at this stage, expression also is detected in the mesodermally derived nephrogenic cord (Figs 3B, 4E).

At E10.5, Six 1 expression is maintained in head mesenchyme, Rathke's pouch and somites. Expression in the somites becomes restricted to the dermomyotome (Fig. 4F). Notochord staining is weaker (Fig. 4F). Six 1 is expressed in neural crest-derived structures such as the nasal placodes, branchial arches and dorsal root ganglia (Fig. 3C). Expression is restricted to a rostral compartment in the mandibular component of the first arch and to a caudal compartment in the second arch (Fig. 3C).

At E11.5, Six 1 expression in the forelimb bud is restricted to a narrow mesenchymal cell population at the posterior limb margin, which extends distally, similar to the direction of limb outgrowth (Fig. 3D).

At E12.5, the expression in the head is more restricted, the dorsal root ganglia expression was maintained and somitic expression was seen in the future body wall muscles (Figs 3E, 6A). Expression in the forelimb extended more anteriorly. At this stage, the different digital condensations are visible (Fig. 3E). Six 1 mRNA is also found in the genitalia, jaw, mandible and tongue (data not shown).

From E.13.5 to E16.0 rather weak expression in most of the body and head skeletal muscles masses was observed (Fig. 5). It is unclear whether expression is restricted to muscles or includes the attached tendons and ligaments. 


\section{Six 1 expression in normal and splotch limb buds}

Expression in developing forelimb is observed first at E10.5 (Figs 3C, 4F, 6D). Initially, the labelling seems to correlate with the two major ventral and dorsal myoblast cells (Fig. 4F). Myoblast precursor cells migrate from the somites to the limb. In order to confirm whether the limb labelling was due to expression in myoblast precursor cells, Six 1 expression was analyzed in splotch mutant mice (splotch is a mutation in the Pax 3 gene (Epstein et al., 1991)). In splotch, myoblast precursor cells do not migrate into the limb. Hence, myogenic genes expression is not seen (Bober et al., 1994). E10.5 splotch homozygote embryos express Six 1 in the limbs (Fig. 6E arrow). However, no labelling was found in the ventral side, and the remaining dorsal expression appeared weaker (Fig. 6F). We conclude that the dorsal, and most of the ventral Six 1 expression corresponds to myogenic precursor cells absent in the limbs of splotch embryos. The remaining dorsal expression is likely to correspond to connective tissue precursors. In order to compare Six 1 expression with the muscle-specific marker, myogenin, we performed ${ }^{35} \mathrm{~S}$-labelled in situ hybridization in paraffin sections of normal E10.5 and E12.5 embryos (Sassoon
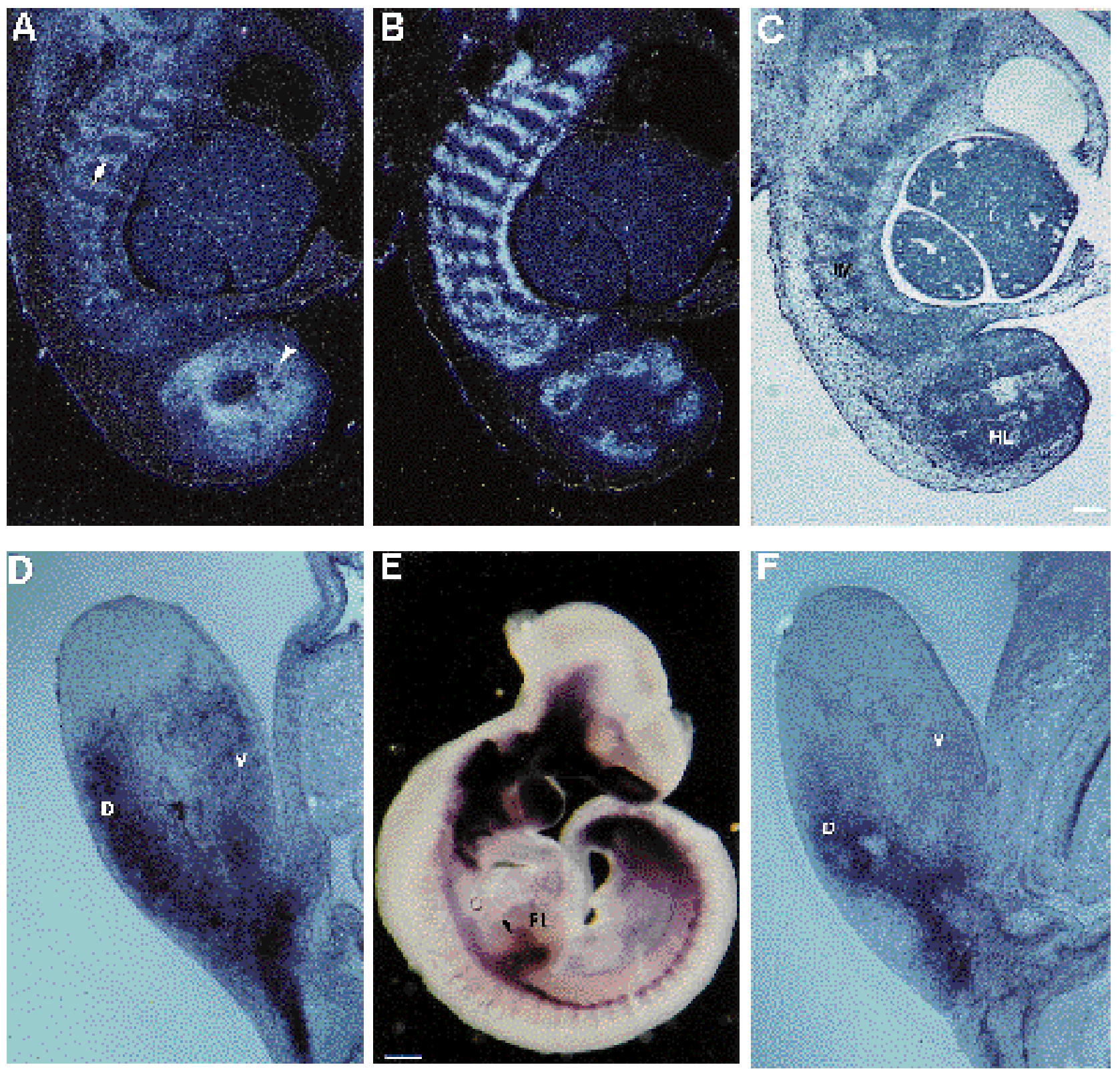

Fig. 6. Six 1 is expressed in myoblast precursors and connective tissue. (A) Dark field of a ${ }^{35}$ S-labelled in situ hybridization on a sagittal section of an E12.5 embryo showing Six 1 mRNA expression in the hindlimb (arrowhead) and in the future intercostal muscles. (B) In situ hybridization over an adjacent section using myogenin as a marker for myoblast cells. (C) Bright field. (D) Normal pattern in an E10.5 limb showing the dorsal (D) and ventral (V) Six 1-expressing-cell populations. (E) Six 1 mRNA remains in the forelimb (FL, arrowhead) of an E10.5 splotch embryo. No dorsal root ganglia are present in this mutant mouse. (F) Section of a limb from a splotch mutant mouse in which (when compared to the normal one in D), it is clear that Six 1 expression in the ventral side is missing and reduced in the dorsal side. HL, hindlimb; IM, intercostal muscles; L, liver; PV, prevertebrae. Scale bar, (A,B,C,D,F) $0.25 \mathrm{~mm}$; (E) $0.1 \mathrm{~mm}$. 
Fig. 7. Six 1 and Six 2 are expressed in tendons and ligaments of the limbs. (A-D) The pattern of Six 1 in whole limbs or in the respective microtome transverse sections at the level of the digits. A similar arrangement is seen for Six 2 in panels A'to D'. (A) At E11.5, expression of Six 1 is located over the posterior limb region $(\mathrm{P})$ both dorsally $(\mathrm{D})$ and ventrally (V). (B) At E12.5, Six 1 mRNA starts to expand anteriorly and is highly expressed over the dorsal side. (C) During E.13.5, the cartilage condensations of the digits are becoming obvious, and in the handplate Six 1 expression is still mostly located over the dorsal side and flanking the cartilage of the digits. (D) At E14.5, Sixl expression shifs, and now it flanks the phalangeal components of the digits anteriorly and posteriorly. (A') At E11.5, Six 2 expression is located in the anterior region (A) and is stronger ventrally than dorsally. (B') Six 2 mRNA expands posteriorly at E 12.5 , and covers approximately the same anteroposterior domain than Six 1 (in both cases, the expression pattern at this stage follows the digit shape) but remains stronger ventrally. (C') Six 2 mRNA at E 13.5 is also flanking the digits cartilage condensations but mostly over the ventral side. (D') At E 14.5, Six 2 has a pattern complementary to Six 1 , it flanks also the phalanges but dorsally (weakly) and mainly ventrally. Scale bar, $0.1 \mathrm{~mm}$.
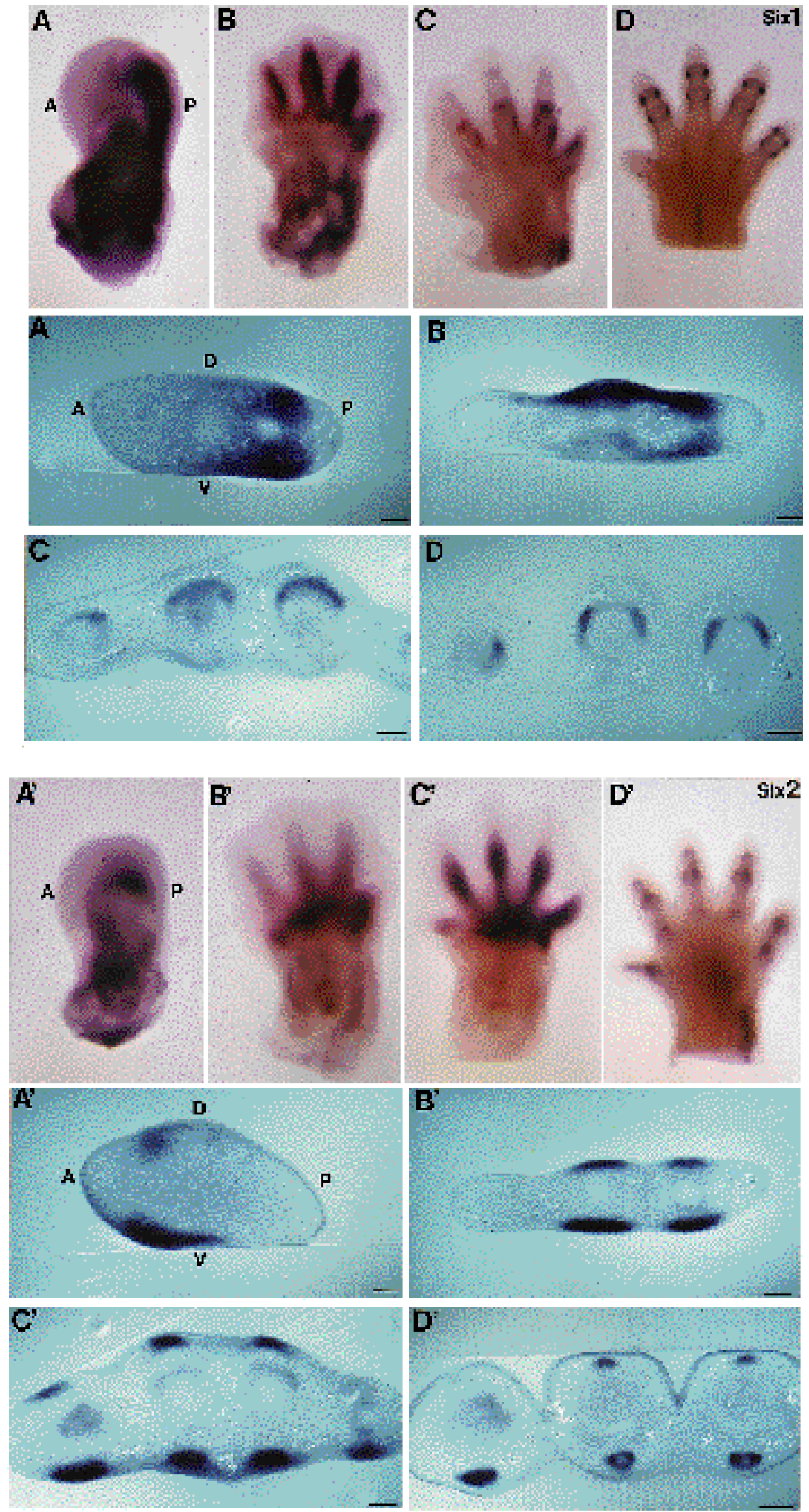

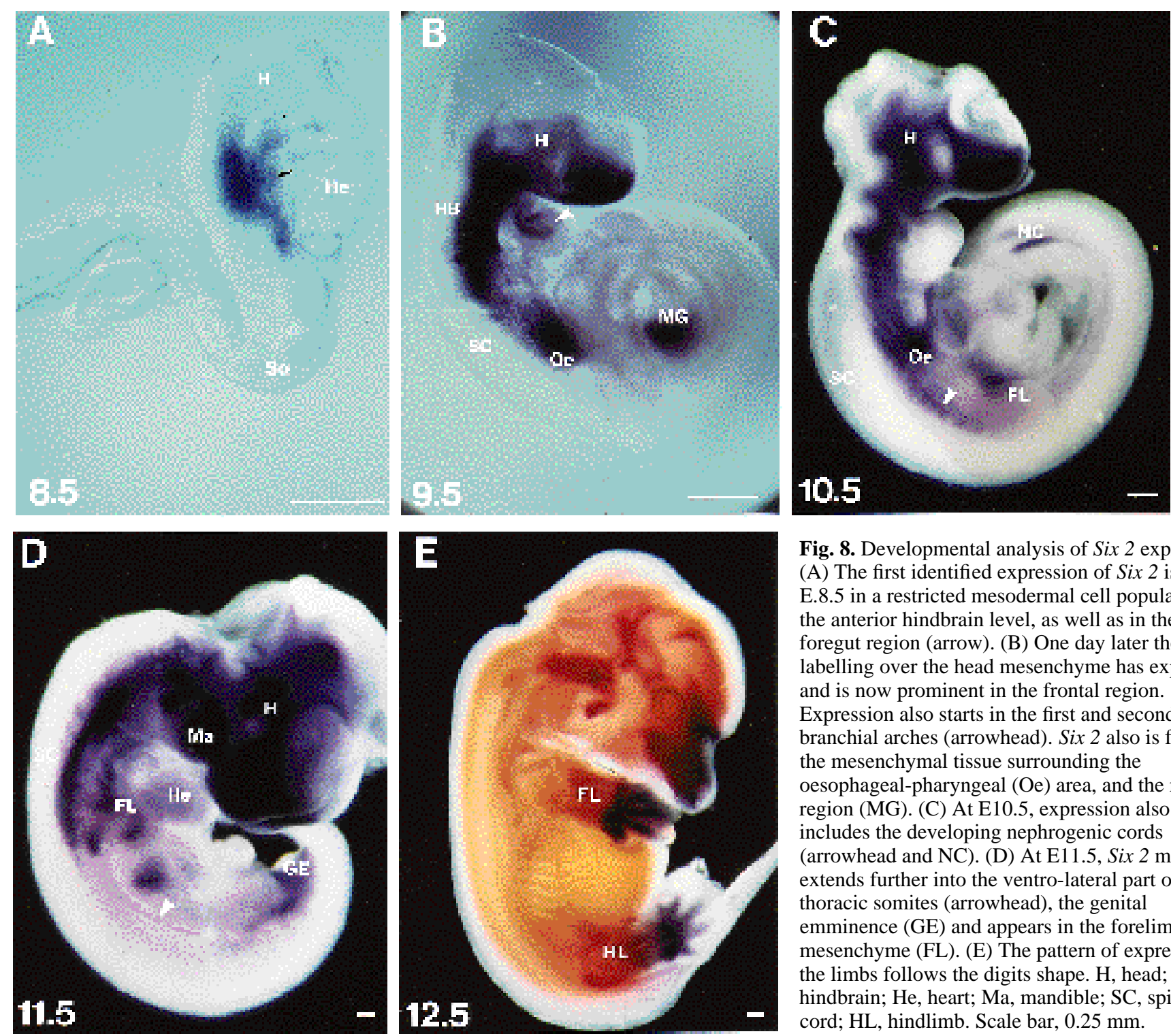

Fig. 8. Developmental analysis of Six 2 expression. (A) The first identified expression of Six 2 is at E.8.5 in a restricted mesodermal cell population at the anterior hindbrain level, as well as in the foregut region (arrow). (B) One day later the labelling over the head mesenchyme has expanded and is now prominent in the frontal region. Expression also starts in the first and second branchial arches (arrowhead). Six 2 also is found in the mesenchymal tissue surrounding the oesophageal-pharyngeal $(\mathrm{Oe})$ area, and the midgut region (MG). (C) At E10.5, expression also includes the developing nephrogenic cords (arrowhead and NC). (D) At E11.5, Six 2 mRNA extends further into the ventro-lateral part of some thoracic somites (arrowhead), the genital emminence (GE) and appears in the forelimb mesenchyme (FL). (E) The pattern of expression in the limbs follows the digits shape. $\mathrm{H}$, head; HB, hindbrain; He, heart; Ma, mandible; SC, spinal cord; HL, hindlimb. Scale bar, $0.25 \mathrm{~mm}$.

et al., 1988). In Fig. 6A,B, the expression patterns for both Six 1 and myogenin are shown in sections of an E12.5 hindlimb. Some of the Six 1-expressing cells also express myogenin. These data suggest that, in the limb, Six 1 is expressed in two different cell populations, migrating myoblast precursor cells and lateral plate-derived connective tissue.

In Fig. 7, the progression of the normal Six 1 expression pattern in the forelimb bud is analyzed in detail. At E11.5 expression is seen in the posterior margin over the dorsal and ventral limb sides (Fig. 7A); expression progresses both anteriorly and distally at E12.5 being now mostly dorsally located (Fig. 7B). At E13.5 (Fig. 7C), individual digits are visible and cartilage begins to condense. Six 1 is expressed dorsally in cells flanking the individual digit condensations. At E14.5 (Fig. 7D), different digits are well formed and separated. Six 1 expression is found in regions flanking phalangeal components anteroposteriorly and remaining weakly expressed dorsally. We can not conclude whether this dorsal to anterior-posterior shift seen at E14.5 reflects suppression of Six 1 expression in dorsal cells, and initiation of expression in cells located in the anterior- posterior flanks, or migration of the dorsal expressing cells anteroposteriorlly. These Six 1 -expressing cells may correspond to those forming connective tissue-derived extensor tendons and ligaments of the phalangeal elements of the digits. Six 1 expression in the developing hindlimb bud is similar (data not shown), but delayed by a few hours.

\section{Analysis of Six 2 gene expression}

Six 2 mRNA is not detected before E8.5. At this stage, expression is restricted to a subclass of cells in head mesoderm, as well as in the foregut (Figs 8A arrow, 9A). Unlike the widely distributed expression of Six 1 mRNA in the head mesoderm at this stage, Six 2 transcripts are only found in a restricted mesodermal cell subpopulation at the hindbrain level (Fig. 8A).

At E9.5 (Fig. 8B), expression in the head becomes more widely distributed, but with a more restricted rostral boundary. Expression may correspond to non-neuronal derivatives of neural crest origin which contribute to the skeletal and connective tissue of the head. Labelling also is observed in a broad band of mesenchymal cells extending caudally from the 

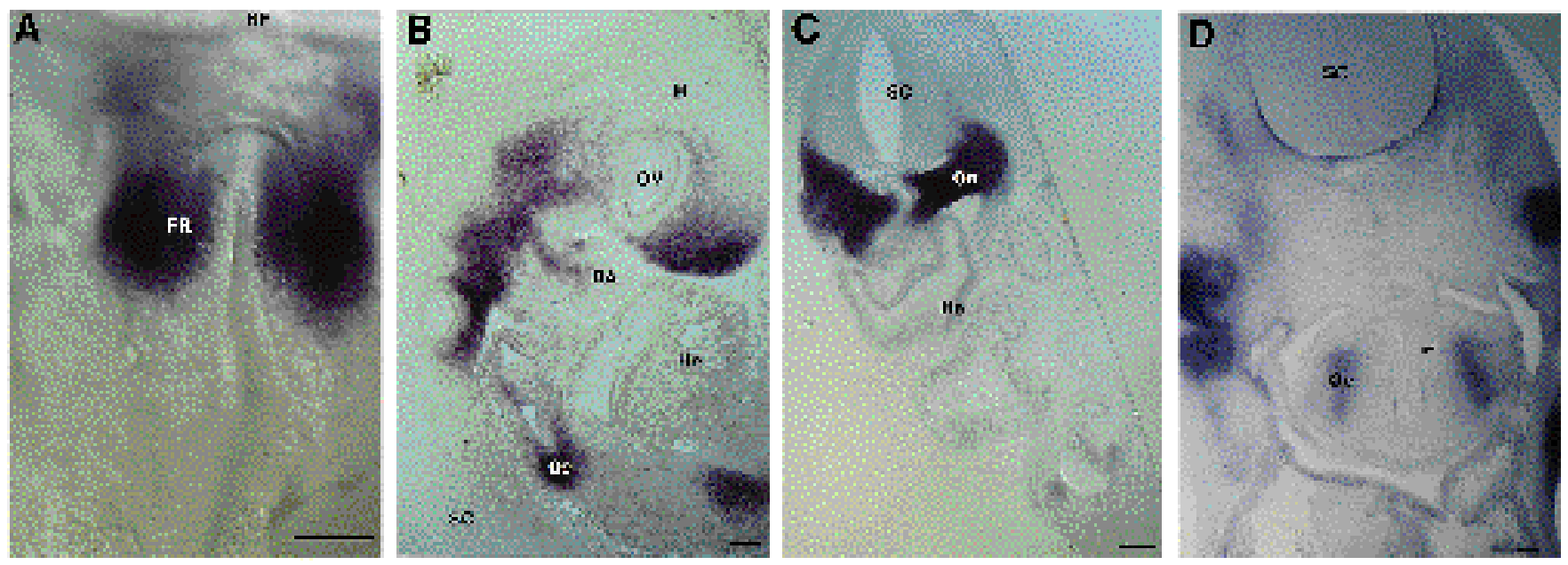

Fig. 9. Detection of Six 2 mRNA in the pharyngeal-oesophageal mesenchyme. (A)Ventral view of an E8.5 embryo in which expression is seen over the very anterior foregut region (FR). (B) Sagittal section of an E9.5 embryo clearly showing Six 2 mRNA in the anterior oesophageal region (Oe). (C) Transverse section of an E10.5 embryo in which most of the mesenchyme surrounding the negative endoderm-derived epithelia of the pharyngeal-oesophageal region strongly expresses Six 2. (D) Detection starts to fade at approximately E12.5 and the remaining Six 2 expression is observed in a restricted mesenchymal cell population (arrow). BA, branchial arches; H, head; He, heart; NF, neural fold; $\mathrm{OV}$, optic vesicle; SC, spinal cord. Scale bar, $0.1 \mathrm{~mm}$.

hindbrain level to the cervical spinal cord (Figs 8B, 9B). Expression of Six 2 also is found in the first and second branchial arches (Figs 8B, 10A). As seen for the engrailed 2 gene in mouse (Logan et al., 1993), the expression invades the medial part of the arches (Fig. 10A). It has been proposed that engrailed 2 expression correspond to cells contributing to the connective tissue of the muscle arches. In addition to arch mesenchyme expression, Six 2 mRNA was restricted to a specific region of the ectoderm between the mandibular and maxillary swellings (Fig. 10A).

Expression also was found in a region of the pharyngeal-
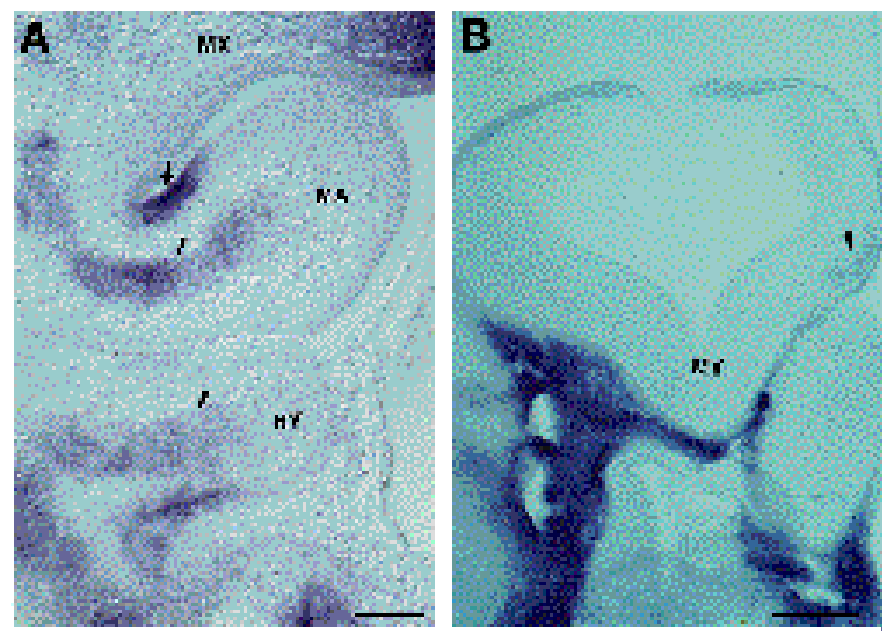

Fig. 10. Six 2 expression also is found in the branchial arches and in a restricted neuroectodermal cell population. (A) Sagittal section of an E10.5 embryo nicely showing a medial string of labelled cells (arrowheads) invading the first (MA, mandible) and second (HY, hyod) branchial arches. It is also possible to see that a small region of the first arch ectoderm (arrow) also expresses Six 2 mRNA.

(B) Transverse section of an E10.5 embryo showing a unique area of neuroectoderm in which this gene is expressed (arrowhead). It corresponds to the myelencephalon (MY) The rest of the labelled tissue is head mesenchyme. MX, maxilla. Scale bar, $0.25 \mathrm{~mm}$.
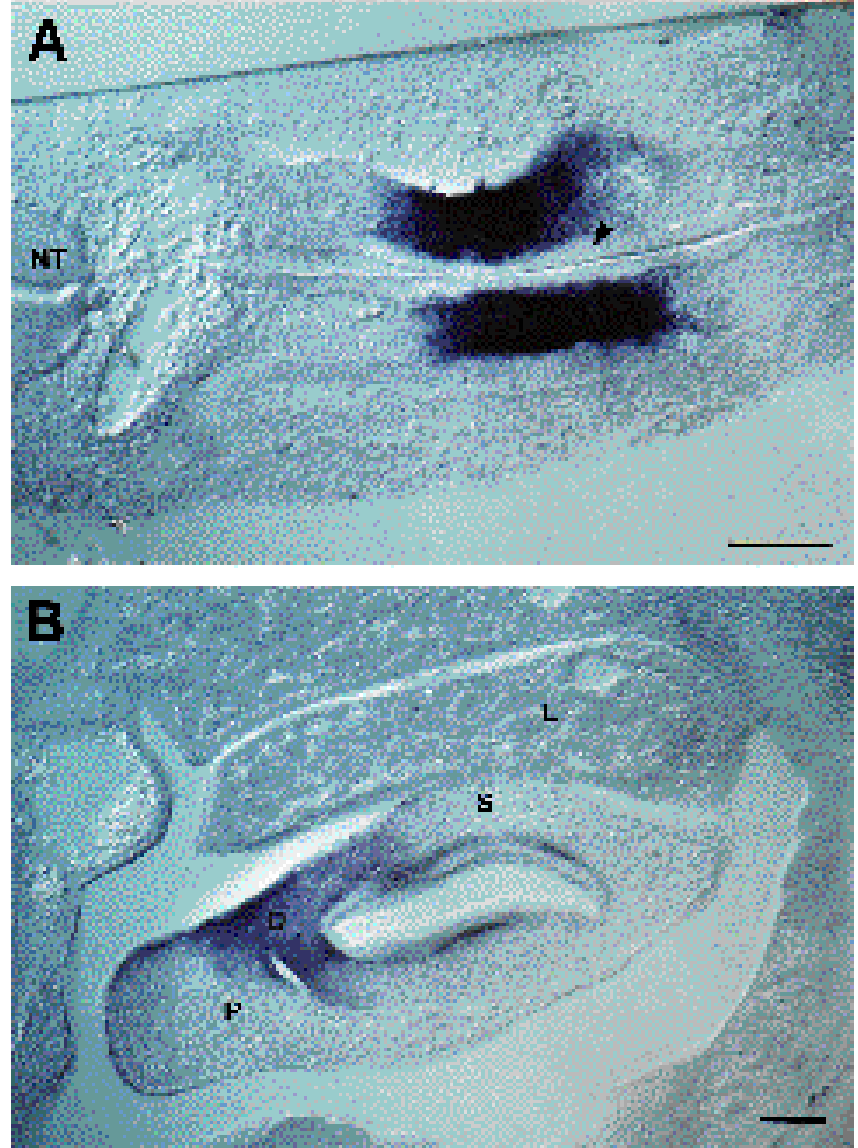

Fig. 11. Six 2 is an early marker for a region of the stomach. (A) Longitudinal section of an E9.5 embryo in which a narrow and anteroposterior limited region of the midgut mesoderm is found to express Six 2. The endoderm-derived epithelia (arrowhead) is not labelled. (B) At E12.5 (saggital section) expression of Six 2 is clearly observed in the mesenchyme corresponding to the gastric-duodenal area (D) in a region that may correspond to the pyloric stomach. L, liver; $\mathrm{P}$, pancreas. Scale bar, $0.1 \mathrm{~mm}$. 

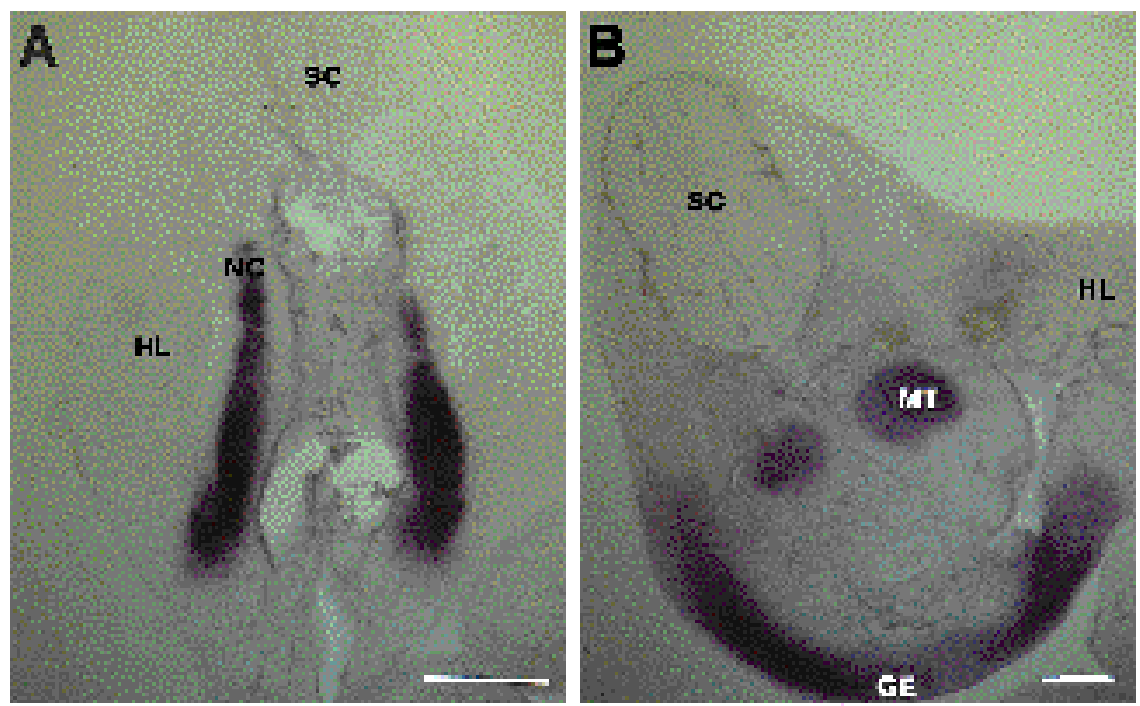

Fig. 12. Developmental expression of Six 2 in the urogenital system. (A) Parasagittal section of an E10.5 embryo in which the Six 2 mRNA is found in the mesenchyme of the posterior nephrogenic cords (NC). (B) At E11.5 (transverse section), the mesonephric tubules (MT) have developed and express Six 2 transcripts in addition to the genital emminence (GE). (C) Dark field of a sagittal section of an E12.5 embryo showing strong silver grain accumulation over the undifferentiated mesenchymal part of the metanephros. The urethric buds (UB) are negative. (D) Bright field. (E) At E14.5 a very localized expression is seen over the genital tubercle mesenchyme (GT). HL, hindlimb; SC, spinal cord; T, tail. Scale bar, (A-D) $0.1 \mathrm{~mm}$; (E) $0.25 \mathrm{~mm}$.
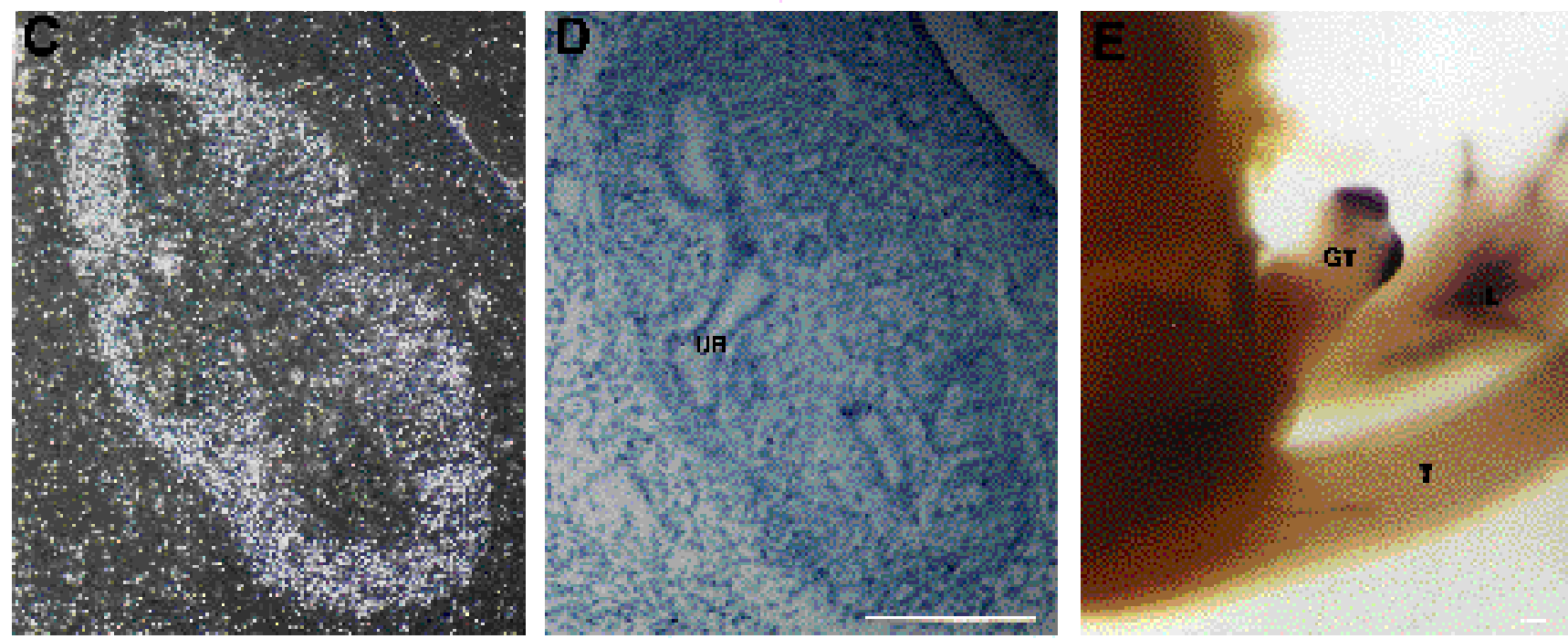

oesophageal mesenchyme (Figs 8B, 9B), and in a restricted area of midgut mesenchyme probably corresponding to the stomach anlage (Figs 8B, 11A). This expression corresponds to the splanchnopleura-derived mesodermal-mesenchymal cells, which produce the future connective tissue and smooth muscle of the viscera.

At E10.5, Six 2 mRNA appears in the developing cervical nephrotomes (arrowhead in Fig. 8C). These are thought to represent a vestige of a primitive kidney. In the more thoracic and lumbar regions, these structures are followed by a pair of elongated and functional mesonephros which are begining to form tubules and are also positive for Six 2 (Figs 8C, 12A). All these tubules are surrounded by mesenchymal cells expressing Six 2 mRNA. In the oesophageal region, labelling is not found in the endodermal part of the tube, but instead in the surrounding mesenchyme (Fig. 9C). At this stage, we found Six 2 expression in neuroectoderm. As seen in Fig. 10B, a small cell population at the anterior part of the hindbrain expresses Six 2 mRNA.

At E.11.5, the band of cervical mesodermal cells has become very evident (Fig. 8D). As development of the excretory system progresses, Six 2 mRNA becomes localized to mes- enchyme of the mesonephric tubules and to the genital eminence (Figs 8D, 12B). During this stage, Six 2 expression commences in the most ventrolateral part of some thoracic somites, and in the forelimb bud (Fig. 8D).

At E12.5, expression in the oesophageal region is limited to regions of supporting smooth muscles and connective tissue (Fig. 9D). The region of the midgut shown to express Six 2 at E9.5, has now adopted its final shape and Six 2 mRNA is mostly localized at the pyloric region, in the junction between stomach and duodenum (Fig. 11B). The abdominal region of the foregut gives rise to the stomach, which is formed by an endodermally derived epithelium surrounded by lateral platederived mesenchyme. During development, the stomach expands and rotates around a craniocaudal axis. The rotation of the stomach and the fusion of the duodenum to the dorsal body wall create an alcove dorsal to the stomach called the lesser sac of the peritoneal cavity (Larsen, 1993). Six 2 expression may correspond to this anatomical region.

Expression in the mesonephros at E12.5 is now restricted to the mesenchyme surrounding the urethric buds of the metanephric kidney (Fig. 12C). Expression also is found over 

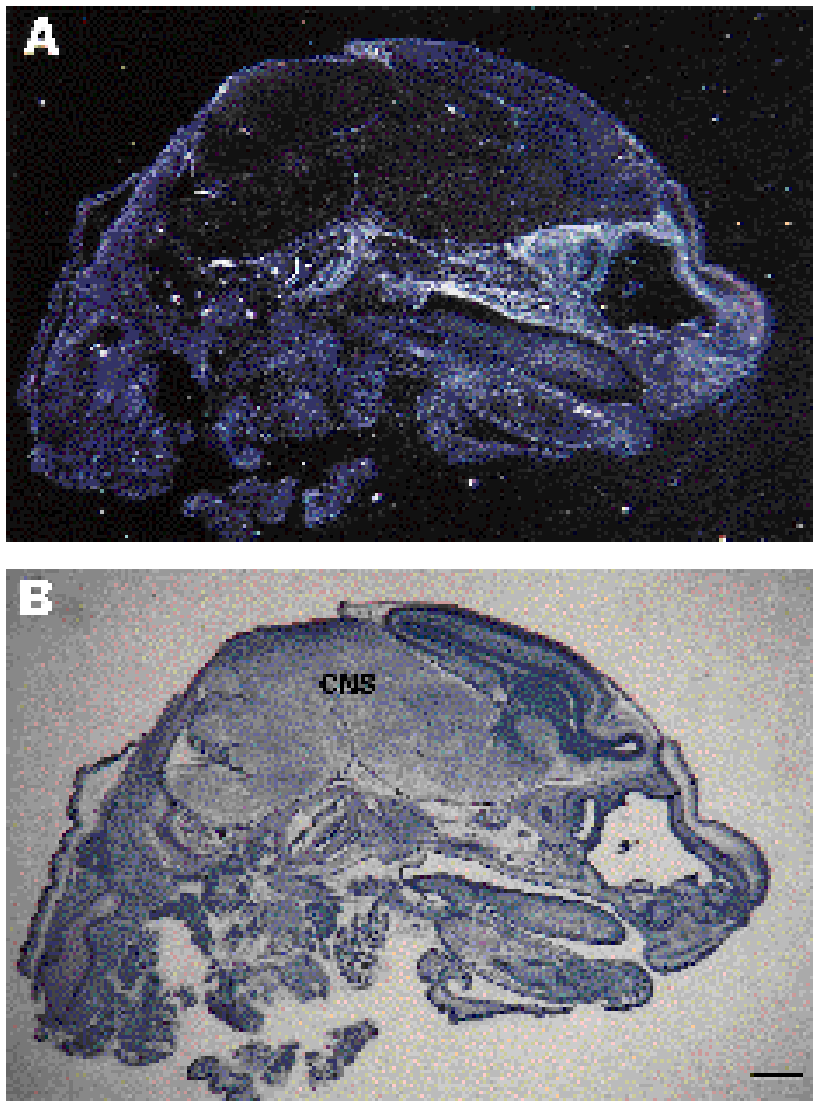

Fig. 13. Six 2 expression at later stages of mouse development. (A) At E15.5 silver grain is found over some of the head membrane bone which are mostly derived from the neural crest. (B) Bright field. CNS, central nervous system. Scale bar, $0.5 \mathrm{~mm}$.

the tip of the genital tubercle (Fig. 12E). Expression in the hindbrain remains as in earlier stages (not shown).

Finally, from E14.5 to E16.0, expression is observed over some of the head bones and weakly in a few head muscles (Fig. 13). Most of these bones are derived from the neural crestderived connective tissue which expresses Six 2. Expression in the oesophagus, stomach and kidney are largely diminished by E16.0 (not shown).

\section{Six 2 expression in limb tendons}

Six 2 expression starts approximately one day later than Six 1 in the developing limb. The first Six 2-expressing cells are found at E11.5 (Fig. 8D).

In Fig. 7, the detailed progression of the Six 2 expression pattern in the developing forelimb is shown. As with Six 1, expression in the hindlimb is similar but a few hours delayed (data not shown). Expression starts at E11.5 (Fig. 7A') as a narrow band along the anterior margin, extending distally similar to the direction of limb growth. At this stage, expression is almost completelly located over the ventral aspect. At E12.5 (Figs 7B', 8E), Six 2 outlines the shape of the different digits as they form. Expression is found in the dorsal and ventral sides of the limb, but it is stronger in the ventral side (Fig. 7B'). At E13.5 (Fig. 7C'), all 5 digits are visible and cartilage condensation commences. Six 2 mRNA remains similar over the dorsal, and especially the ventral side of the limb. At E14.5 (Fig. 7D'), when individual digits become separated, the expression pattern is complementary to that of Six 1. Instead of flanking the cartilage condensations of the different phalangeal elements of the digits anteriorly and posteriorly, Six 2 appears ventrally (strongly) and dorsally (weakly). We propose that Six 2 expression in the limbs also corresponds to tendons and ligaments of the phalangeal elements of the developing digits. However, Six 2 expression seems to be restricted to a different set of tendons (most probably the flexor ones), than the ones expressing Six 1 .

\section{DISCUSSION}

Studies of vertebrate limb development have mostly focused on skeletal elements rather than the more complex pattern formed by the approximately 50 different muscles and 30 different tendons of the wing (Shellswell and Wolpert, 1977; Robson et al., 1994). Genes in the Hox clusters have been suggested to be important players in establishing positional values for skeletal elements along limb axes (Oliver et al., 1989; Kessel and Gruss, 1991; Morgan and Tabin, 1993). To our knowledge, these genes have not been reported to be specifically expressed during limb tendon formation. The discovery of two members of a new highly diverged family of homeodomain proteins reported in this paper raises the exciting prospect that patterning of connective tissue and muscle may be controlled by a unique class of transcription factors.

Using the splotch mouse mutant, the Six 1 expression pattern in the limb was shown to include myoblast precursors and mesenchymal cells. Expression in the limb proceeds from posterior to anterior. In contrast, Six 2 expression pattern develops from anterior to posterior. After E11.0, both genes are expressed in the dorsal and ventral limb; Six 1 stronger dorsally (i.e. probably in the extensor blastemas) while Six 2 is stronger ventrally (i.e. over the flexor blastemas). Upon completion of phalange development, Six 1-expressing cells flank the cartilage condensations mostly anteriorly and posteriorly, while those expressing Six 2 are mostly found dorsally and ventrally. The Six 1 and Six 2 expression patterns in the dorsal and ventral limb, and their proximodistal expansion, coincide with tendon blastema formation (Hurle et al., 1990). The distal limb tendons initially consist of a single dorsal and ventral blastema, which upon further subdivision will give rise to the different tendons that insert in the digit phalanges. As with other limb components, the growth and differentiation of tendons occurs in a proximodistal direction. It is tempting to speculate that Six 1 and Six 2 pattern some of the limb tendons, in particular, the flexors and extensors of the phalangeal elements. Alternatively, Six 1 and Six 2 may specify cell type precursors involved in connective tissue development. It will be interesting to assess the relationship between Six 1 and Six 2 expression and Hox gene expression, previously proposed to pattern skeletal elements.

It has been proposed that the factors that control the final patterning of vertebrate limb skeletal elements are similar to those that control the patterning of tendons and muscles (Shellswell and Wolpert, 1977). This notion is based largely on the finding that manipulations of the chick wing affecting skeletal pattern, also affect the musculature (Shellswell and Wolpert, 1977). In the case of Six 1, expression is not only found in the 
developing connective tissue, but is expressed in the migrating myoblast precursor cells. Hence, Six 1 maybe expressed at the same time both in myoblast precursors migrating from the somite into the limb and in a subpopulation of lateral platederived mesenchymal cells which give rise to the connective tissue. This may guarantee that the tendon and muscle precursor cells expressing the same set of genes adopt similar positional values during their migration in the limb bud. It is also possible that Six 1 and Six 2 expression is responding to positional values previously established in the limb by a combination of other different molecules.

Six 1 was also found expressed in other body regions during early mouse development and, later, in skeletal muscles. Most, if not all, the Six 1-expressing cells will give rise to muscle and connective tissue. In addition to limb expression, Six 2 also was found expressed in some precursors to viscera smooth muscle and associated connective tissue. Later in development, it was found in some crest-derived head bones.

In conclusion, we propose that Six 1 and Six 2 are involved in patterning limb connective tissue (tendons and ligaments). These genes also may subserve this function in other body connective tissue, and in skeletal and smooth body muscles in which they are expressed.

We wish to thank Dr Patrick Tremblay for the splotch animals used in this study, Sabine Geisendorf and Debra J.Gilbert for excellent technical assistance. Ralf Altschäffel for excellent photopgraphic work. We also want to thank Drs Herbert Haack, Michael Kessel, Ed Stuart, Fabienne Pituello and especially Miguel Torres for critical reading of the manuscript. This research was supported by the MaxPlanck Society and in part by the National Cancer Institute, DHHS, under contract NO1-CO-74101 with ABL.

\section{REFERENCES}

Auffray, C. and Rougeon, F . (1980). Purification of mouse immunoglobulin heavy-chain messenger RNAs from total myeloma tumor RNA. Eur. J. Biochem. 107, 303-314.

Bober, E., Franz, T., Arnold, H. H., Gruss, P. and Tremblay, P. (1994). Pax -3 is required for the development of limb muscles: a possible role for the migration of dermomyotomal muscle progenitor cells. Development 120, 603-612.

Bürglin, T. R. (1994). In Guidebook to the Homeobox Genes. (ed. D. Duboule) Oxford: Oxford University Press.

Butler, J., Cosmos, E. and Cauwenbergs, P. C. (1988). Positional signals: evidence for a possible role in muscle fibre-type patterning of the embryonic avian limb. Development 102, 763-772.

Chevallier, A. and Kieny, M. (1982). On the role of the connective tissue in the patterning of the chick limb musculature. Wilhelm Roux's Archiv. Dev. Biol. 191, 277-280.

Cheyette, B. N. R., Green, P. J., Martin, K., Garren, H., Hartenstein, V. and Zipursky, S. L. (1994). The Drosophila sine oculis locus encodes a homeodomain-containing protein required for the development of the entire visual system. Neuron 12, 977-996.

Copeland, N. G. and Jenkins, N. A. (1991). Development and applications of a molecular genetic linkage map of the mouse genome. Trends Genet. 7, 113118.

Epstein, D. J., Vekemans, M. and Gros, P. (1991). Splotch $\left(S p^{2 H}\right)$, a mutation affecting development of the mouse neural tube, shows a deletion within a paired homeodomain of Pax-3. Cell 67, 767-774.

Fishel, R., Lescoe, M. K., Rao, M. R. S., Copeland, N. G., Jenkins, N. A., Garber, J., Kane, M. and Kolodner, R. (1993). The human mutator gene homolog $\mathrm{MSH} 2$ and its association with hereditary nonpolyposis colon cancer. Cell 75, 1027-1038.

Frohman, M. A., Dush, M. K. and Martin, G. R. (1988). Rapid production of full-length cDNAs from rare transcripts amplification using a single genespecific oligonucleotide primer. Proc. Natl. Acad. Sci. USA 85, 8998-9002.

Green, E. L. (1981). Linkage, recombination, and mapping. In Genetics and Probability in Animal Breeding Experiments. Oxford University Press, New York, pp. 77-113.

Green, M. C. (1989). Catalog of mutant genes and polymorphic loci. In Genetic Variants and Strains of the Laboratory Mouse. (ed. M. F. Lyon and A. G. Searle). Oxford University Press, Oxford, England, pp. 12-403.

Hawes, N. L., Langley, S. H. and Roderick, T. H. (1980). Location of syndactylism on Chr 12. Mouse News Lett. 63, 20.

Hurle, J. M., Ros, M. A., Ganan, Y., Macias, D., Critchlow, M. and Hinchliffe, J. R. (1990). Experimental analysis of the role of ECM in the patterning of the distal tendons of the developing limb bud. Cell Differ. Dev. 30, 97-108.

Jenkins, N. A., Copeland, N. G., Taylor, B. A. and Lee, B. K. (1982). Organization, distribution, and stability of endogenous ecotropic murine leukemia virus DNA sequences in chromosomed of Mus musculus. J. Virol. 43, 26-36.

Kessel, M. and Gruss, P. (1991). Homeotic transformations of murine vertebrae and concomitant alteration of Hox codes induced by retinoic acid. Cell 67, 89-104.

Kieny, M. and Chevallier, A. (1979). Autonomy of tendon development in the embryonic chick wing. J. Embryol. Exp. Morphol. 49, 153-165.

Larsen, W. J. (1993). Human Embryology. Churchill Livingstone.

Logan, C., Khoo, W. K., Cado, D. and Joyner, A. L. (1993). Two enhancer regions in the mouse En-2 locus direct expression to the $\mathrm{mid} / \mathrm{hindbrain}$ region and mandibular myoblasts. Development 117, 905-916.

Morgan, B. A. and Tabin, C. J. (1993). The role of homeobox genes in limb development. Current Op. Genet. Dev. 3, 668-674.

Oliver, G., Sidell, N., Fiske, W., Heinzmann, C., Mohandas, T., Sparkes, R. S. and De Robertis, E. M. (1989). Complementary homeo protein gradients in developing limb buds. Genes Dev. 3, 641-650.

Robson, L. G., Kara, T., Crawley, A. and Tickle, C. (1994). Tissue and cellular patterning of the musculature in chick wings. Development 120, 1265-1276.

Sassoon, D., Garner, I. and Buckingham, M. E. (1988). Transcripts for acardiac and a-skeletal actins are early markers for myogenesis in the mouse embryo. Development 104, 155-164.

Saunders, J. W. Jr. (1977). The experimental analysis of chick limb bud development. In Vertebrate Limb and Somite Morphogenesis (eds. D. A. Ede, J. R. Hinchliffe and M. Balls), pp. 1-24. Cambridge: Cambridge University Press.

Shellswell, G. B. and Wolpert, L. (1977). The pattern of muscle and tendon development in the chick wing. In Vertebrate Limb and Somite Morphogenesis (eds. D. A. Ede, J. R. Hinchliffe and M. Balls), pp. 71-86. Cambridge: Cambridge University Press.

Sullivan, G. E. (1962). Anatomy and embryology of the wing musculature of the domestic fowl (Gallus). Aust. J. Zool. 10, 458-516.

Webb, G. C., Jenkins, N. A., Largaespada, D. A., Copeland, N. G., Fernandez, C. S. and Bowtell, D. D. L. (1993). Mammalian homologues of the Drosophila Son of sevenless gene map to murine chromosomes 17 and 12 and to human chromosomes 2 and 14, respectively. Genomics 18, 14-19.

(Accepted 1 December 1994) 